\title{
ANALISIS PERILAKU PENGETAHUAN DALAM INGATAN MELALUI JAWABAN PRE-TEST, POST-TEST DAN KUISIONER MONITORING I-II PESERTA PELATIHAN VOKASIONAL RENCANA USAHA DAN MANAJEMEN KEUANGAN KELOMPOK SWADAYA MASYARAKAT (KSM) BINAAN BUSINESS DEVELOPMENT CENTER (BDC) SRIWIJAYA PALEMBANG
}

\author{
Oleh: \\ Ellys Thoyib, R.Y. Effendi \\ Dosen Tetap Fakultas Ekonomi Universitas IBA
}

\begin{abstract}
The KSM pre-test and post-test vocational training and monitoring questionnaire aimed to determine the extent of KSM's understanding of the material of the Business Plan and Financial Management before and after KSM vocational training. Understanding of training material can be said as knowledge that is responded to by the eyes, the participants' hearing and feelings will then be interpreted and understood in the mind then settles in the memories of participants (J. Paul Peter \& Peter C. Jackson, 2009). Knowledge in participants' memories is so dynamic that it can be said to be a behavior, that is knowledge behavior in memory. Knowledge behavior in this memory was examined through the value of the answers to the pre-test, post-test and training participants I and II questionnaires. The number of participants is $70 \mathrm{KSM}$, but $43 \mathrm{KSMs}$ will be studied and the same people will take part in the pre-test, post-test and monitoring questionnaire I and II. Knowledge behavior in memory is analyzed through the dynamics of the answers to the pre-test to post-test and monitoring I to II. Groups that experience an increase in value are said to be Knowledge Behavior in Memory with Positive Mode and groups that experience impairment are called Negative Modes and groups with stable values are called Consistent Modes. Groups that experience an increase in value are said to be Knowledge Behavior in Memory with Positive Mode and groups that experience impairment are called Negative Modes and groups with stable values are called Consistent Modes. Reward and punishment in the form of periodic and intensive guidance and administration sanctions. Reward and punishment in the form of periodic and intensive guidance and administration sanctions
\end{abstract}

Keyword ; Memory Knowledge Behavior

\section{PENDAHULUAN \\ Latar Belakang}

Program Nasional Kota Tanpa Kumuh (KOTAKU) adalah sebuah upaya Pemerintah untuk membangun kapasitas sosial, ekonomi dan lingkungan (SEL) masyarakat yang produktif, kreatif, inovatif dan mandiri. Masyarakat yang menjadi sasaran program ini adalah kelompok-kelompok swadaya masyarakat yang berkerja disektor 
informal. Pada umumnya masyarakat yang bekerja disektor ini adalah masyarakat yang hidup dilingkungan sosial dengan banyak permasalahan, misalnya permasalahan yang disebut sebagai penyakit masyarakat. Kehidupan ekonomi mereka bertumpu pada usaha berskala kecil atau mikro, seperti jualan pempek dengan pelanggan disekitar rumah atau berjualan disuatu tempat keramaian (pasar) atau membuat jumputan kecil-kecilan untuk dijual kepasar. Tempat tinggal mereka pun umumnya berada dilingkungan yang kurang baik dan kurang layak.

Permasalahan keterampilan SDM, permodalan dan akses pemasaran masih menjadi forsi terbesar bagi usaha kelompok swadaya masyarakat ini. Pemerintah dengan program KOTAKU melakukan kegiatan Pelatihan vokasional Rencana Usaha (Business Plan) dan Manajemen Keuangan untuk KSM binaan BDC Sriwijaya. Pelatihan ini ditujukan untuk meningkatkan keterampilan KSM membuat pempek, kemplang kerupuk dan jumputan. Keterampilan pemasaran off -line dan on line, keterampilan menyusun Rencana Usaha dan analisis kinerja keuangan, pencatatan setiap transaksi pada akun-akun keuangan, menghitung harga pokok produksi, laba rugi, neraca serta mengisi aplikasi sistem pengelolaan informasi keuangan (Si Apik). Setelah pelatihan ini diharapkan KSM dapat menerapkan keterampilan yang diajarkan kepada kegiatan usaha mereka, sehingga dapat berdampak pada peningkatan usaha KSM.

\section{2 . Permasalahan}

Bagaimana Perilaku Pengetahuan Dalam Ingatan KSM melalui Analisis Jawaban Pre-Test, Post-Test Dan Kuisioner Monitoring I-II Peserta Pelatihan Vokasional Rencana Usaha Dan Manajemen Keuangan Kelompok Swadaya Masyarakat (KSM) Binaan Business Development Centre (BDC) Sriwijaya Palembang.

\section{3. Tujuan Penelitian}

1. Untuk mengetahui apakah nilai jawaban pre-test dan post-test serta monitoring I dan II telah menunjukkan ada pengetahuan Rencana Usaha dan Manajemen Keuangan tersimpan didalam ingatan KSM.

2. Untuk mengetahui bagaimana Dinamika Pengetahuan Rencana Usaha dan Manajemen Keuangan yang tersimpan dalam ingatan KSM.

3. Untuk mengetahui bagaimana Modus Perilaku Pengetahuan Rencana Usaha dan Manajemen Keuangan didalam ingatan KSM setelah mendapat pelatihan vokasional Rencana Usaha dan Manajemen Keuangan.

4. Untuk mengetahui tindak lanjut yang harus dilakukan agar pengetahuan Rencana Usaha dan Manajemen Keuangan terus tersimpan didalam ingatan KSM sehingga dapat membentuk sikap dan perilaku disiplin melakukan pencatatan setiap transaksi keuangan serta membuat rencana untuk pengembangan usaha

\section{4. Manfaat Penelitian}

1. Bagi KSM ;

Pengetahuan Rencana Usaha, memberikan pengetahuan agar KSM ahli menganalisis kekuatan, kelemahan, peluang dan tantangan usaha. Menganalisis 
situasi pasar dan pesaing. Menganalisis kinerja keuangan usaha melalui analisis Cash Flow dan Break Even Point serta analisis prospek pengembangan usaha. Sedangkan pengetahuan Manajemen Keuangan, memberikan pengetahuan agar KSM ahli didalam melakukan pencatatan setiap transaksi didalam akun-akun keuangan seperti pencatatan transaksi dibuku Pembelian, Penjualan, Piutang, Persediaan Utang, Kas, menghitung Harga Pokok Penjualan dan Laporan LabaRugi serta Neraca.

2. Bagi Pemerintah ;

Sebagai suatu kebijakan Pemerintah, pemegang amanat UUD 45 khususnya pasal 33 ayat 3 untuk meningkatkan pengetahuan rakyat sebagai sumber daya manusia yang sangat berperan penting untuk melaksanakan pembangunan dan kemajuan bangsa Indonesia.

\section{5. Hasil Yang Diharapkan}

1. Ada suatu pembelajaran tentang perilaku pengetahuan dalam ingatan setelah KSM mendapatkan pelatihan vokasional melalui analisis nilai jawaban pre-test, posttest, monitoring I dan II.

5. Ada Saran-saran yang harus dilakukan sebagai tindak lanjut agar pengetahuan Manajemen Keuangan dan Manajemen Keuangan terus tersimpan didalam ingatan KSM sehingga dapat membentuk sikap dan perilaku disiplin melakukan pencatatan setiap transaksi keuangan dan membuat rencana untuk pengembangan usaha

\section{KAJIAN PUSTAKA}

Bumi dan air dan kekayaan alam yang terkandung didalamnya dikuasai oleh Negara dan dipergunakan untuk sebesar-besar untuk kesejahteraan rakyat (UUD'45; 2017). Pelatihan keterampilan (vokasional) untuk KSM binaan BDC Sriwijaya adalah salah satu upaya untuk meningkatkan keterampilan masyarakat yang berkelompok didalam kelompok swadaya masyarakat bidang usaha pempek, kemplang kerupuk dan jumputan. Menurut Malayu SP, 2010 ; pelatihan adalah usaha untuk meningkatkan pengetahuan, keterampilan dan keahlian SDM sehingga dapat melakukan perkerjaannya secara efektif dan efisien. Pengetahuan yang didapat dari pelatihan akan direspon oleh indera dan tersimpan dalam ingatan sebagai pengetahuan seseorang. (J.Paul Peter \& Peter C. Olson, 2009). Pengetahuan yang tersimpan dalam ingatan akan membentuk pola pikir seseorang. ( Kreitner and Angelo, 2014)). Selanjutnya pola pikir akan teraktualisasi kedalam sikap dan perilaku seseorang. (Miftah Thoha, 2016). Perilaku yang didukung oleh pengetahuan, keterampilan dan keahlian akan membentuk kompetensi seseorang didalam setiap pengambilan keputusan (Erni Tisnawati Sule, 2005). Pengetahuan Rencana Usaha dan Manajemen Keuangan yang didapat peserta pelatihan vokasional merupakan bekal bagi KSM untuk mengambil keputusan bisnis dan pengelola keuangan usaha untuk membangun kinerja keuangan yang akuntabel (IAI Sumsel, 2012). Agar tujuan pelatihan dapat dicapai maka harus dilakukan monitoring dan pembimbingan secara kontinue sebagai motivator kepada KSM untuk memacu usaha mereka sehingga betul-betul menunjukkan kecendrungan ada peningkatan mutu dan penjualan. Menurut Wirawan, 2012 ; monitoring 
merupakan kunci untuk memelihara motivasi segenap sumber daya manusia, progres kinerja, aktifitas dan pengembangannya. Dari nilai jawaban pre-test dan post-test serta kuisioner monitoring I dan II adalah salah satu wujud dari implementasi pengetahuan didalam ingatan perserta pelatihan dan monitoring.

\section{METODOLOGI PENELITIAN}

\section{1. Peserta Pre-test, Post-test dan Monitoring.}

Peserta pelatihan vokasional Manajemen Keuangan dan Manajemen Keuangan adalah kelompok swadaya masyarakat (KSM) binaan BDC Sriwijaya yang berjumlah 70 KSM. Mereka terdiri dari $61 \mathrm{KSM}$ dengan jenis usaha pempek, model, tekwan dan kue. 4 KSM usaha kemplang kerupuk dan 5 KSM pengrajin jumputan. Semua peserta mengikuti pre-test dan post-test, namun yang dimonitoring berjumlah $43 \mathrm{KSM}$ yang dipilih dengan metode stratified sampling. Untuk analisis perilaku pengetahuan dalam ingatan peserta pelatihan maka dipilih peserta yang mengikuti pre-test, post-test dan monitoring.

\section{2. Skema Pengisian Pre-Test, Post-Test dan Kuisioner Monitoring I-II}

Hari pertama jum'at 30 November 2018 materi yang diberikan kepada peserta adalah Rencana Usaha (Business Plan). Peserta dibagi 3 kelas yaitu 41 KSM kelas pempek, 24 KSM kelas kemplang kerupuk, model, tekwan dan nasi. 5 KSM dikelas jumputan. Setelah peserta regestasi, tepat jam 09.00 peserta dipersilakan masuk kedalam kelas, kemudian dilanjutkan membagikan kuisioner pre-test untuk diisi peserta. Pengisian dibimbing oleh pemateri dan pendamping dengan waktu \pm 5 menit. Setelah selesai diisi dikumpulkan oleh panitia. Kemudian kegiatan pelatihan berikutnya adalah penjelasan materi Manajemen Keuangan. Setelah pelatihan selesai, dilanjutkan pengisian post-test yaitu pertanyaan-pertanyaan yang sama dengan pre-test.

Hari kedua sabtu, 1 Desember 2018, materi Manajemen Keuangan. Seperti hari sebelumnya, peserta diberikan lembar pre-test untuk mereka isi. Setelah diisi peserta, dikumpulkan kembali. Kegiatan berikutnya adalah penjelasan materi Keuangan sampai selesai, kemudian pembagian lembar post-test untuk diisi peserta. Setelah selesai diisi dikumpulkan oleh panitia.

\section{3. Media}

\section{Modul}

Kuisioner pre-test, post-test dan monitoring dibuat berdasarkan materi yang ada didalam Modul Rencana Usaha dan Manajemen Keuangan. Modul Rencana Usaha (Business Plan) berisi sub materi sebagai berikut ;

Visi, misi, tujuan usaha, Latar belakang usaha dan gambaran produk, Rencana pemasaran, Analisis Pesaing, Analisis SWOT, Strategi usaha, Rencana anggaran, Analisis Kinerja Keuangan KSM meliputi Analisis cash flow dan BEP, naskah penjualan dan siklus usaha.

Modul Manajemen Keuangan berisi sub materi sebagai berikut ;

Buku Penjualan, buku Pembelian, buku Persediaan Barang, Buku Piutang,buku Utang, buku Kas, Perhitungan harga pokok produksi, Laporan laba rugi, Neraca dan aplikasi sistem pengelolaan informasi keuangan (si Apik) 


\section{Kuisioner Pre-Test dan Post-Test}

Kuisioner pre-test adalah pertanyaan-pertanyaan yang diajukan sebelum pelatihan dimulai, hal ini dimaksudkan untuk menilai sejauhmana pengetahuan peserta terhadap materi pelatihan yang akan dijelaskan. Post-test adalah pertanyaanpertanyaan yang sama yang terdapat pada kuisioner pre-test yang dijawab setelah pelatihan Rencana Usaha atau Manajemen Keuangan selesai. Hal ini dimaksudkan untuk menganalisis pemahaman peserta sebelum dan sesudah pelatihan. Penilaian hasil jawaban pre-test dan post-test dengan memberikan skor 1 untuk setiap pilihan jawaban yang benar dan nilai nol untuk jawaban yang salah.

\section{Kuisioner Monitoring I dan II}

Kuisioner monitoring berisikan pertanyaan-pertanyaan yang berbeda dengan pre-test dan post-test, namun tetap berdasarkan materi Rencana Usaha dan Manajemen Keuangan yang telah diberikan saat pelatihan. Pertanyaan monitoring I adalah sama dengan pertanyaan monitoring II.

\section{4. Penentuan Peserta Monitoring}

Kegiatan monitoring setelah pelatihan adalah sangat penting untuk dilakukan agar dapat mengevaluasi apakah materi pelatihan memang betul-betul dipahami, (Wirawan, 2012). Selanjutnya diharapkan mereka bersedia untuk menerapkan pengetahuan tersebut kedalam kinerja mereka. Monitoring pasca pelatihan Rencana Usaha dan Manajemen Keuangan dapat merupakan salah satu cara memberikan penguatan (reinforcement) serta motivasi kepada KSM untuk selalu disiplin pada pencatatan setiap transaksi keuangan dan membuat analisis Rencana Usaha bagi kemajuan bisnis mereka kedepan. Monitoring dilakukan sebanyak $2 \mathrm{x}$ setelah 1 minggu pasca pelatihan. Metode Perankingan (stratified) digunakan untuk menentukan 5 kelurahan tempat tinggal KSM yang akan menjadi objek monitoring. Pertama-tama perankingan jumlah peserta ditiap kelurahan, yang banyak jumlahnya akan menjadi objek monitoring. Selanjutnya melihat nilai post-test materi Rencana Usaha dan manajemen Keuangan, setelah diberi skor, ditabulasi, kemudian dikelompokkan berdasarkan jumlah peserta yang mendapatkan nilai > 5 disetiap kelurahan, lalu dipilih 5 kelurahan dengan jumlah peserta terbanyak dengan nilai post-test $>$ 5. Untuk lebih jelasnya dapat dilihat pada tabel dibawah ini ; 
Tabel 3.1 Penetapan Lokasi Monitoring

\begin{tabular}{|c|c|c|c|c|c|}
\hline \multirow[t]{2}{*}{ No } & \multirow[t]{2}{*}{ Kelurahan } & \multirow[t]{2}{*}{$\begin{array}{c}\text { Jumlah } \\
\text { KSM }\end{array}$} & \multicolumn{2}{|c|}{$\begin{array}{c}\text { Jumlah peserta } \\
\text { dengan nilai Post- } \\
\text { test }>5\end{array}$} & \multirow[t]{2}{*}{ Jenis produk } \\
\hline & & & $\begin{array}{c}\text { Rencana } \\
\text { Bisnis }\end{array}$ & $\begin{array}{c}\text { Mnj. } \\
\text { Keuangan }\end{array}$ & \\
\hline 1 & Karang Anyar & 18 & 4 & 8 & Pempek+kemplang \\
\hline 2 & 14 Ilir & 16 & 4 & 8 & Pempek \\
\hline 3 & 15 Ilir & 7 & 4 & 3 & Pempek \\
\hline 4 & Tuan Kentang & 5 & 3 & 4 & Pempek \\
\hline 5 & 13 Ilir & 5 & 2 & 3 & Jumputan \\
\hline 6 & Karang Jaya & 5 & - & 1 & Pempek \\
\hline 7 & Talang .Betutu & 3 & - & 1 & Pempek \\
\hline 8 & 2 Ilir & 2 & - & 1 & Pempek \\
\hline 9 & Pulo Kerto & 3 & - & 1 & Pempek \\
\hline 10 & Silaberanti & 1 & - & - & Pempek \\
\hline 11 & 26 Ilir & 2 & - & - & Pempek \\
\hline 12 & Bukit sangkal & 1 & - & - & Pempek \\
\hline 13 & $8 \mathrm{Ulu}$ & 1 & - & - & Pempek \\
\hline 14 & 5 Ilir & 1 & - & - & Pempek \\
\hline
\end{tabular}

Sumber : Daftar hadir peserta dan Rekap nilai postest, 2018 


\section{BAB IV. HASIL DAN ANALISIS}

IV 1. Hasil

Tabel 4.1

Perilaku Pengetahuan Dalam Ingatan Peserta Melalui Analisis Nilai Jawaban PreTest, Post-Test dan Monev I-II Peserta Pelatihan Vokasional Untuk Materi Rencana Usaha

\begin{tabular}{|r|l|c|c|c|c|c|c|l|}
\hline No & Nama Peserta & \multicolumn{2}{|c|}{$\begin{array}{c}\text { Nilai Pre } \\
\text { dan } \\
\text { Post- } \\
\text { Test }\end{array}$} & \multicolumn{2}{|c|}{$\begin{array}{c}\text { Nilai } \\
\text { Monev I }\end{array}$} & $\begin{array}{c}\text { Status } \\
\text { Perilaku } \\
\text { dalam } \\
\text { Pre/Post-test }\end{array}$ & $\begin{array}{c}\text { Status } \\
\text { Perilaku } \\
\text { dalam } \\
\text { Monev I-II }\end{array}$ & $\begin{array}{l}\text { Modus } \\
\text { Perilaku }\end{array}$ \\
\hline 1 & Nur'Ellin & 5 & 6 & 5 & 5 & Naik & Stabil & $\begin{array}{l}\text { Modus } \\
\text { Positif }\end{array}$ \\
\hline 2 & Mazenalina & 5 & 8 & 2 & 5 & Naik & Naik & $\begin{array}{l}\text { Modus } \\
\text { Positif }\end{array}$ \\
\hline 3 & Welyani & 1 & 7 & 5 & 4 & Naik & Turun & $\begin{array}{l}\text { Modus } \\
\text { Negatif }\end{array}$ \\
\hline 4 & Imtilena & 7 & 2 & 2 & 5 & Turun & Naik & $\begin{array}{l}\text { Modus } \\
\text { Negatif }\end{array}$ \\
\hline 5 & Fadhilah .S & 4 & 6 & 2 & 5 & Naik & Naik & $\begin{array}{l}\text { Modus } \\
\text { Positif }\end{array}$ \\
\hline 6 & Fitri Yulianti & 4 & 5 & 2 & 5 & Naik & Naik & $\begin{array}{l}\text { Modus } \\
\text { Positif }\end{array}$ \\
\hline 7 & Sri Hastuti & 3 & 8 & 5 & 5 & Naik & Stabil & $\begin{array}{l}\text { Modus } \\
\text { Positif }\end{array}$ \\
\hline 8 & Mursita & 4 & 2 & 5 & 5 & Turun & Stabil & $\begin{array}{l}\text { Modus } \\
\text { Negatif }\end{array}$ \\
\hline 9 & Hartati & 4 & 6 & 5 & 5 & Naik & Stabil & $\begin{array}{l}\text { Modus } \\
\text { Positif }\end{array}$ \\
\hline 10 & R.A.Lestari & 6 & 2 & 5 & 5 & Turun & Stabil & $\begin{array}{l}\text { Modus } \\
\text { Negatif }\end{array}$ \\
\hline 11 & Siti Komaria & 5 & 5 & 5 & 5 & Stabil & Stabil & $\begin{array}{l}\text { Modus } \\
\text { Konsisten }\end{array}$ \\
\hline 12 & Fitriyanti & 5 & 2 & 5 & 5 & Turun & Stabil & $\begin{array}{l}\text { Modus } \\
\text { Negatif }\end{array}$ \\
\hline 13 & Sunarti & 4 & 7 & 5 & 3 & Naik & Turun & $\begin{array}{l}\text { Modus } \\
\text { Negatif }\end{array}$ \\
\hline 15 & R.A Fitria & 6 & 8 & 5 & 5 & Naik & Stabil & $\begin{array}{l}\text { Modus } \\
\text { Positif }\end{array}$ \\
\hline 16 & Endraini & 4 & 2 & 2 & 4 & Turun & Naik & $\begin{array}{l}\text { Modus } \\
\text { Negatif }\end{array}$ \\
\hline 17 Podiana & 5 & 4 & 1 & 4 & Turun & Naik & $\begin{array}{l}\text { Modus } \\
\text { Negatif }\end{array}$ \\
\hline
\end{tabular}




\begin{tabular}{|c|c|c|c|c|c|c|c|c|}
\hline 18 & Vivi Silvia & 6 & 3 & 5 & 5 & Turun & Stabil & $\begin{array}{l}\text { Modus } \\
\text { Negatif }\end{array}$ \\
\hline 19 & Nurhayati & 2 & 5 & 5 & 5 & Naik & Stabil & $\begin{array}{l}\text { Modus } \\
\text { Positif } \\
\end{array}$ \\
\hline 20 & Shendy & 5 & 6 & 5 & 5 & Naik & Stabil & $\begin{array}{l}\text { Modus } \\
\text { Positif }\end{array}$ \\
\hline 21 & Nurmala.S & 8 & 6 & 5 & 5 & Turun & Stabil & $\begin{array}{l}\text { Modus } \\
\text { Negatif }\end{array}$ \\
\hline 22 & Zaleha & 3 & 5 & 5 & 5 & Naik & Stabil & $\begin{array}{l}\text { Modus } \\
\text { Positif }\end{array}$ \\
\hline 23 & Siti Zubaidah & 4 & 6 & 5 & 5 & Naik & Stabil & $\begin{array}{l}\text { Modus } \\
\text { Positif }\end{array}$ \\
\hline 24 & R.A Salinah & 5 & 6 & 4 & 5 & Naik & Naik & $\begin{array}{l}\text { Modus } \\
\text { Positif }\end{array}$ \\
\hline 25 & $\begin{array}{l}\text { Tri } \\
\text { Wahyunigsih }\end{array}$ & 2 & 2 & 2 & 2 & Stabil & Stabil & $\begin{array}{l}\text { Modus } \\
\text { Negatif }\end{array}$ \\
\hline 26 & Siti Aisyah & 3 & 2 & 2 & 3 & Turun & Naik & $\begin{array}{l}\text { Modus } \\
\text { Positif }\end{array}$ \\
\hline 27 & Rusnani & 7 & 5 & 3 & 3 & Turun & Stabil & $\begin{array}{l}\text { Modus } \\
\text { Negatif }\end{array}$ \\
\hline 28 & Murlaili & 2 & 2 & 5 & 5 & Stabil & Stabil & $\begin{array}{l}\text { Modus } \\
\text { Konsisten }\end{array}$ \\
\hline 29 & Wiwik S & 1 & 2 & 4 & 5 & Naik & Naik & $\begin{array}{l}\text { Modus } \\
\text { Positif }\end{array}$ \\
\hline 30 & Eli Nasti & 9 & 7 & 5 & 5 & Turun & Stabil & $\begin{array}{l}\text { Modus } \\
\text { Negatif }\end{array}$ \\
\hline 31 & Ai Sidartini & 3 & 7 & 3 & 4 & Naik & Naik & $\begin{array}{l}\text { Modus } \\
\text { Positif }\end{array}$ \\
\hline 32 & R.A. Zainoni & 3 & 5 & 4 & 5 & Naik & Naik & $\begin{array}{l}\text { Modus } \\
\text { Positif }\end{array}$ \\
\hline 33 & Umi Kalsum & 3 & 3 & 4 & 5 & Stabil & Naik & $\begin{array}{l}\text { Modus } \\
\text { Positif }\end{array}$ \\
\hline 34 & Zainab & 5 & 8 & 5 & 5 & Naik & Stabil & $\begin{array}{l}\text { Modus } \\
\text { Positif }\end{array}$ \\
\hline 35 & Anisa & 8 & 8 & 5 & 5 & Stabil & Stabil & $\begin{array}{l}\text { Modus } \\
\text { Konsisten }\end{array}$ \\
\hline 36 & Ropiah & 2 & 3 & 2 & 4 & Naik & Naik & $\begin{array}{l}\text { Modus } \\
\text { Positif }\end{array}$ \\
\hline 37 & Sumi & 1 & 4 & 5 & 5 & Naik & Stabil & $\begin{array}{l}\text { Modus } \\
\text { Positif }\end{array}$ \\
\hline 38 & Huzaima & 0 & 7 & 2 & 2 & Naik & Stabil & $\begin{array}{l}\text { Modus } \\
\text { Positif }\end{array}$ \\
\hline 39 & Asmira & 4 & 9 & 5 & 3 & Naik & Turun & $\begin{array}{l}\text { Modus } \\
\text { Negatif }\end{array}$ \\
\hline
\end{tabular}




\begin{tabular}{|c|l|l|c|c|c|c|c|l|}
\hline 40 & Asmi & 6 & 6 & 5 & 4 & Stabil & Turun & $\begin{array}{l}\text { Modus } \\
\text { Negatif }\end{array}$ \\
\hline 41 & Yulia & 7 & 9 & 5 & 5 & Naik & Stabil & $\begin{array}{l}\text { Modus } \\
\text { Positif }\end{array}$ \\
\hline 42 & Pojok & 4 & 5 & 5 & 3 & Naik & Turun & $\begin{array}{l}\text { Modus } \\
\text { Negatif }\end{array}$ \\
\hline 43 & Sartika & 4 & 4 & 5 & 5 & Stabil & Stabil & $\begin{array}{l}\text { Modus } \\
\text { Konsisten }\end{array}$ \\
\hline
\end{tabular}

Sumber : Kuisioner Pre-test, Post-test dan Monitoring I dan II, 2018

Dari Tabel 4.1 diatas dapat dijelaskan tentang dinamika perilaku pengetahuan dalam ingatan peserta untuk materi Rencana Usaha sebagai berikut :

1. Jumlah pertanyaan untuk pre-test Rencana Usaha adalah 12 pertanyaan, nilai tertinggi yang dicapai peserta adalah 9 dan nilai terendah 0 .

2. Jumlah pertanyaan untuk post-test Rencana Usaha adalah 12 pertanyaan, nilai tertinggi yang dicapai peserta adalah 9 dan nilai terendah 2 .

3. Jumlah pertanyaan untuk Monev I Rencana Usaha adalah 5 pertanyaan, nilai tertinggi yang dicapai peserta adalah 5 dan nilai terendah 1 .

4. Jumlah pertanyaan untuk Monev II Rencana Usaha adalah 5 pertanyaan, nilai tertinggi yang dicapai peserta adalah 5 dan nilai terendah 2 .

5. $25(58 \%)$ nilai jawaban peserta dari pre-test ke post-test meningkat.

6. $11(26 \%)$ nilai jawaban peserta dari pre-test ke post-test menurun.

7. $7(16 \%)$ nilai jawaban peserta dari pre-test ke post-test stabil.

8. $13(30 \%)$ nilai jawaban peserta pada monitoring I ke II meningkat.

9. $5(12 \%)$ nilai jawaban peserta pada monitoring I ke II menurun.

10. $25(58 \%)$ nilai jawaban peserta pada monitoring I ke II stabil.

11. Modus perilaku pengetahuan dalam ingatan peserta melalui analisis nilai jawaban pretest, post-test dan monitoring I-II dibagi menjadi 3 kelompok yaitu $22(51 \%)$ peserta bermodus Positif. 16 (37\%) peserta bermodus Negatif, sedangkan sisanya 5 (12\%) peserta bermodus Konsisten.

Tabel 4.2

Perilaku Pengetahuan Dalam Ingatan Peserta Melalui Analisis Nilai Jawaban PreTest, Post-Test dan Monev I-II Peserta Pelatihan Vokasional Untuk Materi Manajemen Keuangan

\begin{tabular}{|r|l|c|c|c|c|c|c|c|}
\hline No & \multicolumn{1}{|c|}{$\begin{array}{c}\text { Nama } \\
\text { Peserta }\end{array}$} & \multicolumn{2}{|c|}{$\begin{array}{c}\text { Nilai Pre } \\
\text { dan Post- } \\
\text { Test }\end{array}$} & \multicolumn{2}{|c|}{$\begin{array}{c}\text { Nilai } \\
\text { Monev I-II }\end{array}$} & $\begin{array}{c}\text { Status } \\
\text { Perilaku } \\
\text { dalam } \\
\text { Pre/Post-test }\end{array}$ & $\begin{array}{c}\text { Status } \\
\text { Perilaku } \\
\text { dalam } \\
\text { Monev I-II }\end{array}$ & $\begin{array}{c}\text { Modus } \\
\text { Perilaku }\end{array}$ \\
\hline 1 & Nur'Ellin & 3 & 5 & 6 & 6 & Naik & Stabil & $\begin{array}{l}\text { Modus } \\
\text { Positif }\end{array}$ \\
\hline 2 & Mazenalina & 7 & 8 & 3,5 & 4,5 & Naik & Naik & $\begin{array}{l}\text { Modus } \\
\text { Positif }\end{array}$ \\
\hline
\end{tabular}




\begin{tabular}{|c|c|c|c|c|c|c|c|c|}
\hline 3 & Welyani & 1 & 4 & 4,5 & 5 & Naik & Naik & $\begin{array}{l}\text { Modus } \\
\text { Positif }\end{array}$ \\
\hline 4 & Imtilena & 6 & 3 & 3 & 5 & Turun & Naik & $\begin{array}{l}\text { Modus } \\
\text { Negatif }\end{array}$ \\
\hline 5 & Fadhilah .S & 3 & 10 & 4 & 6 & Naik & Naik & $\begin{array}{l}\text { Modus } \\
\text { Positif }\end{array}$ \\
\hline 6 & Fitri Yulianti & 7 & 5 & 3 & 4,5 & Turun & Naik & $\begin{array}{l}\text { Modus } \\
\text { Negatif }\end{array}$ \\
\hline 7 & Sri Hastuti & 4 & 3 & 3 & 4,5 & Turun & Naik & $\begin{array}{l}\text { Modus } \\
\text { Negatif }\end{array}$ \\
\hline 8 & Mursita & 3 & 5 & 6 & 6 & Naik & Stabil & $\begin{array}{l}\text { Modus } \\
\text { Positif }\end{array}$ \\
\hline 9 & Hartati & 0 & 6 & 6 & 4 & Naik & Turun & $\begin{array}{l}\text { Modus } \\
\text { Positif }\end{array}$ \\
\hline 10 & R.A.Lestari & 7 & 9 & 6 & 6 & Naik & Stabil & $\begin{array}{l}\text { Modus } \\
\text { Positif }\end{array}$ \\
\hline 11 & Siti Komaria & 6 & 6 & 5,5 & 5,5 & Stabil & Stabil & $\begin{array}{l}\text { Modus } \\
\text { Konsisten }\end{array}$ \\
\hline 12 & Fitriyanti & 4 & 10 & 6 & 4 & Naik & Naik & $\begin{array}{l}\text { Modus } \\
\text { Positif }\end{array}$ \\
\hline 13 & Sunarti & 8 & 8 & 6 & 6 & Stabil & Stabil & $\begin{array}{l}\text { Modus } \\
\text { Positif }\end{array}$ \\
\hline 14 & R.A Fitria & 5 & 6 & 6 & 6 & Naik & Stabil & $\begin{array}{l}\text { Modus } \\
\text { Positif }\end{array}$ \\
\hline 15 & Susanti & 6 & 5 & 6 & 6 & Turun & Stabil & $\begin{array}{l}\text { Modus } \\
\text { Negatif }\end{array}$ \\
\hline 16 & Endraini & 4 & 7 & 5 & 6 & Naik & Naik & $\begin{array}{l}\text { Modus } \\
\text { Positif }\end{array}$ \\
\hline 17 & Herliana & 3 & 8 & 5,5 & 5 & Naik & Turun & $\begin{array}{l}\text { Modus } \\
\text { Negatif }\end{array}$ \\
\hline 18 & Vivi Silvia & 5 & 5 & 6 & 6 & Stabil & Stabil & $\begin{array}{l}\text { Modus } \\
\text { Konsisten }\end{array}$ \\
\hline 19 & Nurhayati & 5 & 4 & 5,5 & 6 & Turun & Naik & $\begin{array}{l}\text { Modus } \\
\text { Negatif }\end{array}$ \\
\hline 20 & Shendy & 3 & 6 & 6 & 6 & Naik & Naik & $\begin{array}{l}\text { Modus } \\
\text { Positif }\end{array}$ \\
\hline 21 & Nurmala.S & 6 & 8 & 6 & 6 & Naik & Stabil & $\begin{array}{l}\text { Modus } \\
\text { Positif }\end{array}$ \\
\hline 22 & Zaleha & 7 & 5 & 5 & 6 & Turun & Naik & $\begin{array}{l}\text { Modus } \\
\text { Negatif }\end{array}$ \\
\hline 23 & $\begin{array}{l}\text { Siti } \\
\text { Zubaidah }\end{array}$ & 8 & 7 & 4,5 & 5 & Turun & Naik & $\begin{array}{l}\text { Modus } \\
\text { Negatif }\end{array}$ \\
\hline 24 & R.A Salinah & 3 & 4 & 5,5 & 6 & Naik & Naik & $\begin{array}{l}\text { Modus } \\
\text { Positif }\end{array}$ \\
\hline
\end{tabular}




\begin{tabular}{|c|c|c|c|c|c|c|c|c|}
\hline 25 & $\begin{array}{l}\text { Tri } \\
\text { Wahyunigsih }\end{array}$ & 5 & 8 & 5 & 6 & Naik & Naik & $\begin{array}{l}\text { Modus } \\
\text { Positif }\end{array}$ \\
\hline 26 & Siti Aisyah & 3 & 6 & 5 & 5 & Naik & Stabil & $\begin{array}{l}\text { Modus } \\
\text { Positif } \\
\end{array}$ \\
\hline 27 & Rusnani & 6 & 6 & 5 & 6 & Stabil & Naik & $\begin{array}{l}\text { Modus } \\
\text { Positif }\end{array}$ \\
\hline 28 & Murlaili & 4 & 1 & 4 & 4 & Turun & Stabil & $\begin{array}{l}\text { Modus } \\
\text { Negatif }\end{array}$ \\
\hline 29 & Wiwik S & 7 & 8 & 5 & 5,5 & Naik & Naik & $\begin{array}{l}\text { Modus } \\
\text { Positif }\end{array}$ \\
\hline 30 & Eli Nasti & 4 & 7 & 5,5 & 6 & Naik & Naik & $\begin{array}{l}\text { Modus } \\
\text { Positif }\end{array}$ \\
\hline 31 & Ai Sidartini & 3 & 7 & 6 & 6 & Naik & Stabil & $\begin{array}{l}\text { Modus } \\
\text { Positif }\end{array}$ \\
\hline 32 & R.A. Zainoni & 4 & 6 & 5 & 6 & Naik & Naik & $\begin{array}{l}\text { Modus } \\
\text { Positif }\end{array}$ \\
\hline 33 & Umi Kalsum & 6 & 5 & 5,5 & 5 & Turun & Turun & $\begin{array}{l}\text { Modus } \\
\text { Negatif }\end{array}$ \\
\hline 34 & Zainab & 6 & 5 & 4,5 & 4,5 & Turun & Stabil & $\begin{array}{l}\text { Modus } \\
\text { Negatif }\end{array}$ \\
\hline 35 & Anisa & 4 & 2 & 5,5 & 6 & Turun & Naik & $\begin{array}{l}\text { Modus } \\
\text { Negatif }\end{array}$ \\
\hline 36 & Ropiah & 2 & 4 & 5 & 6 & Naik & Naik & $\begin{array}{l}\text { Modus } \\
\text { Positif }\end{array}$ \\
\hline 37 & Sumi & 2 & 4 & 4 & 4 & Naik & Stabil & $\begin{array}{l}\text { Modus } \\
\text { Positif }\end{array}$ \\
\hline 38 & Huzaima & 2 & 2 & 5 & 5 & Stabil & Stabil & $\begin{array}{l}\text { Modus } \\
\text { Konsisten }\end{array}$ \\
\hline 39 & Asmira & 2 & 5 & 4,5 & 6 & Naik & Naik & $\begin{array}{l}\text { Modus } \\
\text { Positif }\end{array}$ \\
\hline 40 & Asmi & 6 & 6 & 4,5 & 6 & Stabil & Naik & $\begin{array}{l}\text { Modus } \\
\text { Positif }\end{array}$ \\
\hline 41 & Yulia & 6 & 8 & 6 & 6 & Naik & Stabil & $\begin{array}{l}\text { Modus } \\
\text { Positif }\end{array}$ \\
\hline 42 & Pojok & 2 & 6 & 4 & 6 & Naik & Naik & $\begin{array}{l}\text { Modus } \\
\text { Positif }\end{array}$ \\
\hline 43 & Sartika & 3 & 6 & 6 & 6 & Naik & Stabil & $\begin{array}{l}\text { Modus } \\
\text { Positif }\end{array}$ \\
\hline
\end{tabular}

Sumber : Kuisioner Pre-test, Post-test dan Monitoring I dan II, 2018

Dari Tabel 4.2 diatas dapat dijelaskan tentang dinamika perilaku pengetahuan dalam ingatan peserta untuk materi Manajemen Keuangan sebagai berikut :

1. Jumlah pertanyaan untuk pre-test Manajemen Keuangan adalah 12 pertanyaan, nilai tertinggi yang dicapai peserta adalah 9 dan nilai terendah 0 .

2. Jumlah pertanyaan untuk post-test Manajemen Keuangan adalah 12 pertanyaan, nilai tertinggi yang dicapai peserta adalah 9 dan nilai terendah 2 . 
3. Jumlah pertanyaan untuk Monev I Manajemen Keuangan adalah 5 pertanyaan, nilai tertinggi yang dicapai peserta adalah 5 dan nilai terendah 1 .

4. Jumlah pertanyaan untuk Monev II Manajemen Keuangan adalah 5 pertanyaan, nilai tertinggi yang dicapai peserta adalah 5 dan nilai terendah 2 .

5. $25(58 \%)$ nilai jawaban peserta dari pre-test ke post-test meningkat.

6. $11(26 \%)$ nilai jawaban peserta dari pre-test ke post-test menurun.

7. $7(16 \%)$ nilai jawaban peserta dari pre-test ke post-test stabil.

8. $13(30 \%)$ nilai jawaban peserta pada monitoring I ke II meningkat.

9. $5(12 \%)$ nilai jawaban peserta pada monitoring I ke II menurun.

10. $25(58 \%)$ nilai jawaban peserta pada monitoring I ke II stabil.

11. Modus perilaku pengetahuan dalam ingatan peserta melalui analisis nilai jawaban pretest, post-test dan monitoring I-II dibagi menjadi 3 kelompok yaitu $28(65 \%)$ peserta Modus Positif. 12 (28\%) peserta Modus Negatif, sedangkan sisanya $3(7 \%)$ peserta Modus Konsisten.

\section{IV.2. ANALISIS}

Pelatihan vokasional KSM binaan BDC Sriwijaya ditujukan untuk memberikan pemahaman tentang pentingnya pencatatan keuangan dan rencana pengembangan usaha. Kebiasaan mencatat setiap transaksi keuangan akan memudahkan KSM dan stakeholder's mengetahui gambaran kinerja keuangan usaha. Prospek pengembangan usaha KSM menjadi fokus utama Pemerintah dengan memberikan pelatihan ini. Diharapkan KSM tidak lagi sebagai pengusaha kecil tapi berkembang sebagai pengusaha menengah atau besar.

Membiasakan KSM melakukan pencatatan setiap transaksi pembelian dan penjualan selama mengelola usaha bukanlah pekerjaan yang mudah. Pelatihan vokasional yang diberikan kepada KSM adalah usaha untuk meningkatkan pengetahuan, keterampilan dan keahlian peserta (Malayu, SP; 2010) sehingga dapat melakukan perkerjaannya secara efektif dan efisien. Pelatihan vokasional Rencana Usaha dan Manajemen keuangan akan menjadi stimulus awal untuk memulai kebiasaan baru kepada peserta. Stimulus ini akan direspon oleh indera dan akan tersimpan dalam ingatan sebagai pengetahuan seseorang dalam hal ini peserta pelatihan.(J. Paul Peter \& Peter C. Olson, 2009). Selanjutnya pengetahuan ini akan menjadi motorik untuk bersikap dan berperilaku. Sikap dan perilaku ini harus didukung dengan frekuensi penguatan (reinforcement) yang intensif agar tidak hilang begitu saja. Seperti dalam teori Pavlov ( dalam J.Paul Peter \& Peter C. Olson, 2009) mengatakan bahwa "kebiasaan yang muncul secara konsisten selalu dikuatkan oleh stimulus yang teratur dan intensif." Pada dasarnya manusia itu lebih suka melakukan halhal yang mudah dan ringan, walaupun disisi lain suka pada hal-hal yang menantang. Menurut Mc.Gregor (dalam Garry desller, 2010), bahwa setiap orang memilki 2 sisi perilaku, disatu sisi manusia senang bekerja dan disisi lain malas berkerja. Untuk mengendalikan 2 sisi perilaku ini manusia perlu diberikan reward dan punishment agar manusia itu mau dan senang mengerjakan pekerjaan yang baik untuk mencapai tujuan usaha.

Reward dan punishment adalah bagian dari proses monitoring dimana peserta dievaluasi kembali atas pemahamannya terhadap materi yang telah diberikan. Hasil 
evaluasi akan dinilai, bagi yang mendapat nilai baik diberikan pujian sedangkan yang mendapat nilai kurang baik akan dibimbing. Untuk itu didalam kegiatan pelatihan vokasional KSM, dilakukan kegiatan pre-test, post-test dan monitoring. Kemudian hasilnya akan dianalisis untuk mengetahui bagaimana Modus perilaku pengetahuan dalam ingatan peserta malalui jawaban pre-test, post-test dan monitoring ?. Modus perilaku pengetahuan dalam ingatan dikelompokkan menjadi 3 kelompok modus yaitu Modus Positif, Modus Negatif dan Modus Konsisten.

\section{IV.2.1 Modus Positif}

Modus Positif dapat dikatakan sebagai kuantitas atau banyaknya nilai jawaban yang menunjukkan perilaku pengetahuan dalam ingatan yang meningkat dari nilai pre-test ke nilai post-test atau dari Monitoring I ke II. Modus Positif juga dapat terjadi dimana nilai pre-test ke nilai post-test meningkat sedangkan nilai Monitoring I ke II stabil dan sebaliknya. Pada materi Rencana Usaha, Modus Positif perilaku pengetahuan dalam ingatan adalah sebesar 22 (51\%). Sedangkan Modus Positif perilaku pengetahuan dalam ingatan peserta materi Manajemen Keuangan adalah adalah sebesar 28 (65\%). Hal dapat diasumsikan bahwa lebih $50 \%$ peserta merespon pengetahuan Rencana Usaha dan Manajemen Keuangan kemudian menyimpannya kedalam ingatan mereka. Agar pengetahuan ini terus tersimpan dalam ingatan maka dibutuhkan stimulus untuk penguatan (reinforcement) berupa reward dan punishment. Reward dapat berupa pembimbingan secara berkala untuk materi tersebut. Sedangkan punishment dengan melakukan evaluasi dan penilaian secara berkala kepada kinerja KSM. Menurut Howthorne (dalam Tisnawati Sule, 2005); reward dan punishment adalah cara membimbing seseorang sehingga orang tersebut merasa diperhatikan dan diawasi agar ada semangat dan perasaan senang untuk melakukan pekerjaannya.

\subsection{Modus Negatif}

Modus Negatif dapat dikatakan sebagai kuantitas atau banyaknya nilai jawaban yang menunjukkan perilaku pengetahuan dalam ingatan yang menurun dari nilai pre-test ke nilai post-test atau dari nilai monitoring I ke II. Modus Negatif juga dapat terjadi dimana nilai pre-test ke nilai post-test meningkat sedangkan nilai Monitoring I ke II menurun. Dapat juga nilai pre-test ke post-test menurun sedang nilai monitoring I ke II meningkat atau stabil. Peserta yang masuk kedalam kelompok Modus Negatif untuk materi Rencana Usaha sebanyak 16 (37\%), sedangkan untuk materi Manajemen Keuangan berjumlah 12 (28\%). Kelompok peserta yang berada pada kelompok Modus Negatif dapat diasumsikan karena kurang fokus didalam merespon pengatahuan yang diberikan sehingga lemah didalam ingatannya. Biasanya orang-orang yang kurang fokus termasuk kepada tipe orang-orang yang memilki type $X$ yaitu cenderung bersifat pasif, dan malas (Mc.Gregor / dalam, Dessler, 2010). Selanjutnya Griffin, 2014; berpendapat bahwa karena kurangnya motivasi. Selain reward kelompok ini membutuhkan punishment administratif misalnya selain dibimbing secara beerkala, kelompok ini harus diberikan tugas-tugas latihan secara intensif. 


\section{2.3 Modus Konsisten}

Modus Konsisten dapat dikatakan sebagai kuantitas atau banyaknya nilai jawaban yang menunjukkan perilaku pengetahuan dalam ingatan yang stabil, baik untuk nilai jawaban dari nilai pre-test ke nilai post-test atau dari nilai monitoring I ke II. Untuk materi Rencana Usaha kelompok Modus Konsisten sebanyak 3 (7\%) peserta sedangkan materi Manajemen Keuangan sebanyak 5 (12\%). Reward dan punishment untuk kelompok Modus Konsisten dapat berupa pembimbingan secara berkala dan sanksi administratif berupa pemberian tugas-tugas latihan menyusun rencana usaha dan laporan keuangan.

\section{KESIMPULAN DAN SARAN}

\section{1. Kesimpulan}

1. Membiasakan mencatat, membuat Manajemen Keuangan, menyusun progres dan program usaha adalah aktifitas yang sangat membutuhkan pembimbingan.

2. Perilaku pengetahuan dalam ingatan peserta tergambar dari nilai jawaban pre-test, post-test, monitoring Idan II, yaitu dari naik /turun /stabil dari status perilaku nilai jawaban pre-test ke post-test dan monitoring I ke II setiap peserta Pelatihan Vokasional Rencana Usaha dan Manajemen Keuangan.

3. Ada dinamika perilaku pengetahuan dalam ingatan peserta untuk materi Rencana Usaha dan Manajemen Keuangan. (tabel 4.1 dan 4.2)

4. Ada 3 Modus Perilaku pengetahuan dalam ingatan KSM untuk materi Rencana Usaha dan Manajemen Keuangan setelah mendapat pelatihan vokasional. Modus perilaku tersebut adalah Modus Perilaku Positif, Negatif dan Konsisten.

5. Harus ada reward dan punishment berupa pembimbingan secara berkala, intensif dan pemberian sanksi administrasi.

\section{2. Saran-saran}

1. Untuk membiasakan KSM melakukan pencatatan sebaiknya BDC sebagai Lembaga Pembina, menyediakan blanko buku-buku pencatatan transaksi usaha seperti buku pembelian, buku penjualan, buku piutang, buku utang dan buku kas.

2. Kegiatan monitoring dan pembinaan yang dilakukan BDC bukan hanya sebatas kegiatan administratif tapi lebih kuat lagi kepada kegiatan observasi operasional usaha.

3. BDC harus menjadi fasilitator yang berintegritas dalam menghubungkan kebijakan-kebijakan Pemerintah dengan kebutuhan pengembangan usaha KSM.

4. BDC harus menjadi mitra usaha KSM yang dapat memberikan solusi bagi permasalahan KSM.

5. Manajemen BDC harus profesional dengan memposisikan hidup mati usaha KSM sebagai tanggung jawabnya.

6. BDC dapat bekerjasama dengan Perguruan Tinggi untuk menjadi tenaga monitoring dan pembimbingan bagi KSM secara kontinue. 


\section{DAFTAR PUSTAKA}

Cara uji paired sample T-Test dan Interpretasi dengan SPSS On Line 3 Desember 2018; http://www.spss indonesia.com/2016/08

Computer Wahana. 2017. Mudah Menguasai SPSS. Yokyakarta. Andi.

Dessler Gary. 2015. Manajemen Sumber Daya Manusia, Terjemahan. Edisi 14. Salemba Empat. Jakarta.

Griffin, 2014. Perilaku Organisasi. Terjemahan. Salemba Empat. Jakarta.

Hasibuan Malayu.S.P, 2010. Manajemen Sumber Daya Manusia. Bumi Aksara, Jakarta.

Pustaka, IAI Sumatera Selatan, 2012.

Peter J.Paul \& Peter C.Olson. 2009. Perilaku Konsumen (Consumer Behavior). Terjemahan. Salemba Empat. Jakarta.

Kreitner Robert \& Angelo Kenichi. 2014. Perilaku Organisasi. Terjemahan. Salemba Empat. Jakarta

Soegiono, 2003. Metodologi Penelitian. Bumi Aksara, Bandung.

Thoha Mifthah. 2016. Perilaku Organisasi, Konsep Dasar dan Aplikasinya. Radja Grafindo Persada. Jakarta

Tisnawati Sule Ernie, Kurniawan Saefullah. 2005. Pengantar Manajemen. Kencana. Jakarta

Wirawan, 2012. Evaluasi Kinerja Sumber Daya Manusia. Salemba Empat. Jakarta 